2 Shapiro SS, Hultin M. Acquired inhibitors to the blood coagulation factors. Semin Thromb Hemostas $1975 ; 1: 336-85$.

${ }^{3}$ Galton DAG. The chronic leukaemias. In: Hoffbrand AV, ed. Recent advances in haematology (3). London: Churchill Livingstone, 1982: 195-6.

4 Wenz B, Friedman G. Acquired factor VIII inhibitor in a patient with malignant lymphoma. Am $\mathcal{F}$ Med Sci 1974;268:295-99.

5 Glueck HI, Hong R. A circulating anticoagulant in multiple myeloma: its modification by penicillin. $\mathcal{F}$ Clin Invest 1965;44:1866-81.

(Accepted 30 April 1982)

Department of Haematology, East Birmingham Hospital, Birmingham B9 5ST

P R KELSEY, MB, MRCP, registrar

M J LEYLAND, MSC, MRCP, consultant physician

$17 \times 2$

\section{Serum and cyst concentrations of mebendazole and flubendazole in hydatid disease}

Since Bekhti et al ${ }^{1}$ described the successful treatment of four patients with hydatid cysts by mebendazole there have been many other reports of its successful use, but widespread scepticism remains. Several months often elapse before there is any noticeable improvement in patients, and doses of up to $200 \mathrm{mg} / \mathrm{kg}$ have been used. Serious side effects are rare, though haemopoietic depression and transient rise of transaminase activities have occurred, and fever is relatively common in the first few days of treatment. ${ }^{2}$ Osborne ${ }^{3}$ could not detect mebendazole in venous blood or cyst fluid of his patient; Bryceson, ${ }^{4}$ however, reported serum concentrations of $20-160 \mu \mathrm{g} / 1$. We measured mebendazole concentration in the serum of seven patients and from the fluid of six cysts (five patients).

\section{Patients, methods, and results}

Seven patients with active hydatid disease were studied; all were being treated with mebendazole $50 \mathrm{mg} / \mathrm{kg} /$ day in divided doses, and five were undergoing elective surgery. It has been recommended that mebendazole is taken with meals, as concomitant fat ingestion may improve its poor absorption. In the two patients not undergoing operation the last dose of mebendazole was given with food; in the remaining patients the last dose before sampling was given before operation without food. All patients had been treated for one week before sampling. Samples of serum and cyst fluid were taken four hours after drug ingestion (during operation in five patients undergoing surgery). The serum and cyst fluid was frozen and transported to Belgium for measurement of drug concentrations. The technique used antibody to mebendazole produced in rabbits by repeated injection of the mebendazole derivative chemically coupled to bovine serum albumin. ${ }^{5}$ This method allows assay of plasma concentrations of mebendazole as low as $100 \mathrm{ng} / \mathrm{l}$. Serum concentrations were mostly between 10 and $20 \mu \mathrm{g} / \mathrm{l}$, and cyst concentrations were even lower, on average being below $1 \mu \mathrm{g} / \mathrm{l}$ (see table).

Serum and cyst concentrations of mebendazole in seven patients studied

\begin{tabular}{|c|c|c|c|}
\hline Case No & Site of cyst & $\begin{array}{c}\text { Serum concentration } \\
(\mu \mathrm{g} / \mathrm{l})\end{array}$ & $\begin{array}{c}\text { Cyst concentration } \\
(\mu \mathrm{g} / \mathrm{l})\end{array}$ \\
\hline 1 & Hepatic & $37 \cdot 2$ & 0.7 \\
\hline 2 & Hepatic & $14 \cdot 5$ & $\left\{\begin{array}{l}0.4 \\
0.7\end{array}\right.$ \\
\hline $\begin{array}{l}3 \\
4 \\
5 \\
6 \\
7\end{array}$ & $\begin{array}{l}\text { Hepatic } \\
\text { Hepatic } \\
\text { Hepatic* } \\
\text { Splenic } \\
\text { Pulmonary }\end{array}$ & $\begin{array}{c}13 \cdot 7 \\
25 \cdot 8 \\
84 \\
9 \cdot 9 \\
13 \cdot 4\end{array}$ & $\begin{array}{r}14.5 \\
1.6 \\
1.2\end{array}$ \\
\hline
\end{tabular}

*Non-paracytic cyst.

One patient (case No 5) with very high serum and cyst concentrations in fact had a simple hepatic cyst that was misdiagnosed as a hydatid.

Flubendazole is a related benzimidazole compound that is available as a sterile suspension and thus would seem to have an advantage over oral mebendazole, which is extremely insoluble and is thus poorly absorbed. This suspension was administered subcutaneously to 10 white female rats at $100 \mathrm{mg} / \mathrm{kg} /$ day at various intervals. The rats were exsanguinated four hours after dose, and flubendazole concentrations measured using technique as described for mebendazole. At one week a concentration of only $2 \cdot 2$ $\mu \mathrm{g} / \mathrm{l}$ was achieved rising to $6.4 \mu \mathrm{g} / \mathrm{l}$ after two weeks, $13.4 \mu \mathrm{g} / \mathrm{l}$ after three, and $12 \cdot 4 \mu \mathrm{g} / \mathrm{l}$ after four. The gradual rise in flubendazole concentration is due to the slow release of the drug from the injected suspension, which is known to occur over at least five days. This is considerably different from the pharmacokinetics of orally administered mebendazole, the half life of which is around four hours.

\section{Comment}

Though this is a small study, the serum concentrations of flubendazole achieved are not encouraging. The use of subcutaneous or intramuscular flubendazole in man would seem unlikely to offer an improvement over the use of oral mebendazole. Mebendazole penetrates large hepatic and pulmonary cysts in man, though in very small quantities. An improved formulation of these compounds that could provide higher serum and cyst concentrations is at present under active investigation.

We are grateful to Mr L D Abrams, Professor P Bevan, Mr V Brookes, Mr J G Gray, Mr D J Oakland, Mr H B Ross, and Dr J Wood for allowing us to study their patients. We also acknowledge the help of Dr J Heykants and his colleagues (Janssen, Beerse, Belgium) who assayed the samples.

${ }^{1}$ Bekhti A, Schaaps JP, Capron M, Dessaint JP, Santofo F, Capron A. Treatment of hydatid disease with mebendazole-preliminary results in four cases. $\mathrm{Br} \mathrm{Med} \mathcal{F} 1977$;ii:1047-51.

${ }^{2}$ Murray-Lyon IM, Reynolds KW. Complications of mebendazole treatment for hydatid disease. $B r$ Med f 1979; ii:1111-2.

${ }^{3}$ Osborne DR. Mebendazole and hydatid disease. Br Med f 1980;280:183.

${ }^{4}$ Bryceson A. Br Med f 1980;280:796.

${ }^{5}$ Michiels M, Hendriks R, Thijssen J, Heykants J. The pharmacokinetics of mebendazole and flubendazole in animals and man. Arch Int Pharmacodyn Ther 1982;256:180-91.

(Accepted 28 April 1982)

The General Hospital, Birmingham B4 6NH

D L MORRIS, FRCS, surgical research fellow

Janssen Pharmaceuticals, Marlow, Bucks

$S$ E GOULD, PHD, MPS, research associate

\section{Localised chondrocalcinosis in unstable joints}

Deposition of calcium pyrophosphate dihydrate crystals in articular cartilage (chondrocalcinosis) is a common, age-related phenomenon. Although a few cases are familial and some are caused by metabolic disorders such as hyperparathyroidism, most are sporadic, idiopathic cases in the elderly. ${ }^{1}$ Deposits may be asymptomatic but are commonly associated with attacks of crystal synovitis (pseudogout) or chronic joint damage (pyrophosphate arthropathy). ${ }^{2}$

The causes of sporadic chondrocalcinosis are unknown and the nature of its association with arthritis unclear. It is widely believed that a generalised abnormality predisposes to crystal deposition and that the crystals then cause the joint disease. ${ }^{3}$ We describe four patients who developed localised chondrocalcinosis in previously damaged, unstable joints.

\section{Case reports}

Case 1-A 37-year-old woman had injured her left knee, rupturing the anterior cruciate ligament, when aged 16 . From the age of 28 she had suffered repeated attacks of synovitis of the left knee. The synovial fluid contained numerous crystals typical of calcium pyrophosphate dihydrate on polarised light microscopy, and a radiographic joint survey showed linear chondrocalcinosis in the menisci of the left knee. There was no family history of arthritis, and metabolic screening for the known associations of chondrocalcinosis yielded negative results.

Case 2-A 48-year-old man with peroneal muscular atrophy, causing instability of the ankles, presented with acute synovitis of his right ankle. Synovial fluid was aspirated and contained pyrophosphate crystals. Radiographic screening showed chondrocalcinosis in both ankles and mid-tarsal joints but nowhere else. His other joints remained clinically normal; there was no family history of arthritis and no metabolic abnormality to account for the chrondrocalcinosis.

Case 3-A 36-year-old woman presented with pain at the base of her 
thumbs. She had a history of "double-jointed" thumb, and had pain, tenderness, and abnormal laxity of her first carpometacarpal joints. The other joints were clinically normal, and there was no evidence of generalised hypermobility. Radiography showed chondrocalcinosis and osteoarthritis of the carpometacarpal joints, and aspiration confirmed the presence of pyrophosphate crystals. Metabolic screening for diseases associated with chrondrocalcinosis yielded negative results.

Case 4-A 52-year-old man presented after a self-limiting attack of acute synovitis of his right knee. At the age of 23 he had undergone right medial meniscectomy for a meniscus tear, and on examination there was laxity of the collateral ligaments. Radiographs showed osteoarthritic changes in the right knee and linear calcification in the lateral meniscus; the other joints were normal. There was no family history of arthritis, and no metabolic abnormality was found.

\section{Comment}

Each of the four patients described developed chondrocalcinosis when relatively young, and the phenomenon was isolated to joints that had been unstable for many years. The presence of pyrophosphate crystals was confirmed by polarised light microscopy in three cases, and no familial or metabolic predisposition was apparent.

An association between generalised joint laxity and chondrocalcinosis was first described in 1978.4 This association might be due to a systemic defect of connective tissue predisposing to both hypermobility and cartilage calcification or to local mechanical factors. Our findings argue in favour of local changes in unstable joints. phenomenon, developing in previously damaged joints. Thus some patients diagnosed as having pseudogout or pyrophosphate arthropathy may have a different primary joint disease. This report also shows that chondrocalcinosis may be caused by local biomechanical factors and not by a systemic or generalised abnormality. These findings contrast with current concepts of this disease. ${ }^{135}$

${ }^{1}$ McCarty D. Calcium pyrophosphate dihydrate crystal deposition disease1975. Arthritis Rheum 1976;19:275-85.

2 Dieppe PA, Alexander G, Jones $\mathrm{H}$, et al. Pyrophosphate arthropathy: a clinical and radiological study of 105 cases. Ann Rheum Dis (in press).

${ }^{3}$ Resnick D, Niwayama G. Calcium pyrophosphate dihydrate crystal deposition disease. In: Resnick D, Niwayama G, eds. Diagnosis of bone and joint diseases. Vol 2. Philadelphia, London, Toronto: W B Saunders, $1981: 1520-74$

${ }^{4}$ Bird HA, Tribe CR, Bacon PA. Joint hypermobility leading to osteoarthrosis and chondrocalcinosis. Ann Rheum Dis 1978;37:203-11.

${ }^{5}$ Howell DS. Diseases due to the deposition of calcium pyrophosphate and hydroxyapatite. In: Kelley WN, Harris ED, Ruddy S, Sledge CB, eds. Saunders, $1981: 1438-54$.

(Accepted 28 April 1982)

University Department of Medicine, Rheumatology Unit, Bristol Royal Infirmary, Bristol BS2 8HW

LUCAS SETTAS, MD, registrar in rheumatology

MICHAEL DOHERTY, MA, MRCP, research fellow

PAUL DIEPPE, BSC, MRCP, senior lecturer
These cases suggest that chondrocalcinosis may be a secondary Textbook of rheumatology. Philadelphia, London, Toronto: W B

On examination he was distressed but not shocked. There was generalised toneum did not show the dense fibrinous reaction associated with

\section{Delayed rupture of stomach after blunt abdominal trauma}

I describe what I believe is the first recorded case of delayed rupture of the stomach after blunt abdominal trauma.

\section{Case report}

A 25-year-old man presented to the casualty department 17 days after the car that he had been driving had been in collision with a bus. He had not been wearing a seat belt, and the steering wheel had struck the lower chest and upper abdomen. From the moment of injury he had suffered a constant dull ache confined to the upper abdomen. This he had treated by circumtruncal bandaging. He continued working as a roof asphalter and could eat, though with discomfort. Sixteen days after the injury, while working on a roof, he had experienced severe, generalised abdomithal pain of sudden onset which had lasted for eight hours. Four hours before admission, one hour after drinking a pint of beer, he had experienced a second episode of this pain, which persisted. He had no history of dyspepsia. and rebound abdominal tenderness with intense guarding. Chest and abdominal radiographs were normal and there was mild leucocytosis. Laparotomy showed an anterior perforation of the stomach $2 \mathrm{~cm}$ long, near the midpoint of the lesser curve. There was a localised area of contamination but no widespread peritoneal soiling, adhesion formation, or mature abscess. Biopsy was performed and the perforation repaired. He made an uncomplicated recovery.

Histologically there was no evidence of peptic or stress ulceration but "the edge of a perforation compatible with a traumatic lesion of a few days' standing."

\section{Comment}

Gastric rupture afer blunt abdominal trauma is rare. A review of cases published since 1930, including the comprehensive analysis of Yajko et al, shows that, although delays in diagnosis have been recognised late rupture of the stomach has not. ${ }^{1-4}$

Three principal points suggest that this case represents a true delayed or late rupture. Firstly, on historical grounds the rupture occurred 24 hours before admission when there was a sudden onset of severe, generalised abdominal pain whereas for the previous 16 days there had been a dull ache confined to the upper abdomen, consistent with injury without perforation. Secondly, at laparotomy the periprolonged contamination. Thirdly, histology showed no evidence of prolonged inflammation, stress ulcer, or peptic ulcer.

The mechanism of injury in rupture of a hollow viscus is regarded as crushing of the organ by direct impact, especially over the vertebral prominence; shearing forces at sites where mobile parts meet fixed parts such as the duodenojejunal flexure; or sudden increase in intraluminal pressure in a segment isolated by the injuring force or by anatomical fixity.

Experimental studies show that rises in intraluminal pressure cause a sequential rupture of the wall of the stomach: firstly the seromuscular coat, then the mucosa, and finally the submucosa. ${ }^{5}$ If the third mechanism of injury is accepted and the experimental model holds good then it may be postulated that an incomplete rupture may have occurred at the time of the initial insult. This incomplete rupture may have left a fragile barrier, perhaps only the submucosa, to complete perforation. A further increase in intraluminal pressure such as might be occasioned by an increase in intra-abdominal pressure while working as a roof asphalter may then complete the perforation.

I thank Mr W R O'Flynn of the Greenwich District Hospital for allowing me to report this case.

1 Yajko RD, Seydel F, Trimble C. Rupture of the stomach from blunt abdominal trauma. $\mathcal{F}$ Trauma $1975 ; 15: 177-83$.

${ }^{2}$ Richardson G, Schiller WR, Shuck J. Gastric rupture from blunt trauma. Rocky Mt Med f 1979;76:309-10.

${ }^{3}$ Siemans RA, Fulton RL. Gastric rupture as a result of blunt trauma. Am Surg 1977;43:229-33.

4 Vora NM, Glassman CI. Rupture of the stomach due to blunt abdominal trauma. Del Med F 1977;49:521-3.

5 Silbergleit A, Berkas EM. Neonatal gastric rupture. Minn Med 1966;49: $65-8$.

(Accepted 20 April 1982)

Greenwich District Hospital, London SE10 9HE

R G LLOYD, FRCS, registrar

MEDICINES HOT IN THE SECOND DEGREE-These are something hotter than the natural temper of a man. Their use for such whose stomachs are filled with moisture, because their faculty is too hot and dry; they take away obstructions or stoppings, open the pores of the skin, but not in the same manner that such do as are hot in the first degree, for they do it without force, by a gentle heat, concocting, and expelling the humours, by strengthening and helping nature in the work; but these cut tough humours, and scatter them by their own force and power when nature cannot.

MEDICINES HOT IN THE FOURTH DEGREE-Those medicines obtain the highest degree of heat, which are so hot that they burn the body of a man, being outwardly applied to it, and cause inflammations, or raise blisters, as Crowfoot, Mustard-seed, Onions, \&c. Of these more hereafter. (Nicholas Culpeper (1616-54) The Complete Herbal, 1850.) 